\title{
Enterprise Information Systems' Interoperability: Focus on PLM Challenges
}

\author{
Dorsaf Elheni-Daldoul $^{1,2}$, Julien Le Duigou ${ }^{1, *}$, Benoit Eynard ${ }^{1}$, \\ and Sonia Hajri-Gabouj ${ }^{2}$ \\ ${ }^{1}$ UTC, Université de Technologie de Compiègne, Département Génie des Systèmes \\ Mécaniques, UMR CNRS 7337 Roberval, BP 60319 - 60203 Compiègne Cedex, France \\ julien.le-duigou@utc.fr, benoit.eynardautc.fr \\ ${ }^{2}$ INSAT, Institut National des Sciences Appliquées et de Technologie, URAII \\ Centre Urbain Nord BP 676 - 1080 Tunis Cedex, Tunisie \\ daldouldorsaf@yahoo.fr, Sonia.Gabouj@insat.rnu.tn
}

\begin{abstract}
Nowadays, in industry, the interoperability of Information Systems throughout the product's life cycle is primordial for a successful Product Lifecycle Management approach. However, there are still scientific and technological locks that prevent the integration of information between enterprise Information Systems. Especially, the lack of interoperability between Product Data Management systems, Manufacturing Process Management and Enterprise Resource Planning to be able to ensure a continuous and bidirectional information flow from the design to the manufacturing and the assembling of a product. This paper presents firstly a literature review of research works developed to define and solve the problems of interoperability in general terms. Then, it exposes most of the recent works on interoperability on the product development linking the different Product Lifecycle Management tools. Finally we proposed an approach to guarantee the interoperability of Product Data Management, Manufacturing Process Management and Enterprise Resource Planning systems.
\end{abstract}

Keywords: Interoperability, PDM, ERP, MPM, Integration.

\section{Introduction}

The PLM strategy can be defined as a solution addressing many components for managing product data (Porter, 1987; Amann, 2002). In industrial companies, PLM has become a paradigm for several decades. It is the process of managing all phases of a product's life cycle (design, manufacturing, sale, recycling) which effectively provides a method to integrate and share product information from department to department within a company, and also externally. It also increases business productivity in terms of cost, quality and time (Terzy et al., 2010).

\footnotetext{
* Corresponding author.
} 
To preserve the overall coherence of the company information system, the interoperability of Information Systems (IS) must be guaranteed throughout a product's life (Noel and Roucoules, 2010). Among these, we mention PDM software (essential in design), that drive virtual product development, also ERP (used in manufacturing) which manages real product.

This paper presents firstly a state of the art of interoperability: definition and levels of interoperability. Then, it exposes specific works on interoperability on the product development linking the different Product Lifecycle Management tools. Finally it concludes on a framework integrating PDM, MPM and ERP.

\section{Definition of Interoperability}

Interoperability still means many things to many people and is often interpreted in many different ways with different expectations (Chen and Doumeingts, 2003). So, in the literature, we find different definitions of the interoperability. IEEE defined the interoperability as "The ability of two or more systems or elements to exchange information and to use the information that has been exchanged" (IEEE, 1990). Also, projects (ATHENA, 2003) and (INTEROP, 2003) define it as the ability of interaction between enterprises (or part of it). So, the enterprise interoperability is achieved if the interaction can, at least, take place at the three levels: data, application and business process. In summary enterprise interoperability is the ability to (a) communicate and exchange information; (b) use the information exchanged; (c) access to functionality of a third system (Chen and Doumeingts, 2003).

Here, interoperability is defined as "The ability of two systems (or more) to communicate, cooperate and exchange services and data, thus despite the differences in languages, implementations, executive environments and abstraction models" (Wegner, 1996).

\subsection{Levels of Interoperability}

According to (EIF, 2004), there are three levels of interoperability: the technical, semantic and organizational levels. The technical level ensures the continuity of the semantic flow (e.g. technology solutions, standards and tools for the exchange of data between IS). The semantic level ensures the sharing of information and service for preserving the semantic flow. And the organizational level concerns the business unit, process and people interactions across organization borders (Paviot et al., 2011). Most articles in the literature tend to satisfy the technical and semantic levels (Paviot et al., 2011; Assouroko et al., 2010). In fact, organizational barriers are additional barriers. Compared with technical barriers (concerned with machine problems) and semantic barriers (centered on information problems), organizational barriers originate from the problem of humans (Chen, 2009). In this research we will focus on the technical and semantic levels. 


\subsection{Semantic Level}

From (ISO, 1999; Kosanke, 2006), there are three manners of achieving semantic interoperability: integration (there exists a common format for all models), unification (there is a common format but it only exists at meta-level) and federation (it is a more recent approach, based on the use of ontologies and Semantic Web standards for automation in the transfer and mapping of data between heterogeneous applications (Assouroko et al., 2010)).

Most of the works in the literature use unification approaches (Paviot et al., 2011; Tursi et al., 2009), because it is more flexible and dynamic than the integration approach. According to (Paviot et al., 2011; Benaben et al., 2008), the use of the STEP standard has the potential to save up to one billion dollars per year by reducing interoperability coasts in the automotive, aerospace and shipbuilding industries. So, the STEP standard is a possible way for the product driven interoperability. On the other hand, the federation approach requires modifying the ontology according to ontology of higher level. As there it may be several top-level ontologies, which implies that the ontology which is chosen must be regularly updated and the mappings are built manually (Hoffman, 2008). However, the federation approach seems to be appropriate and interesting for the interoperability of IS of PLM, despite the disappointing results on methods and tools for ontology alignment (Pratt, 2005).

\subsection{Technical Level}

According to (Booth et al., 2004), Web services provide a standard means of interoperating between different software applications, running on a variety of platforms and/or frameworks. The trend, today, of major PLM commercial products becoming Service Oriented Architecture (SOA) (e.g. TeamCenter, Windchill, SAP, etc.) invites us to explore this direction to ensure the technical interoperability of IS.

The mediator architecture is also a promising solution for treat the problems of interoperability (Benaben et al., 2008; Wiederhold, 1992). In fact, the mediator architecture is more efficient in terms of agility of IS and the total cost of ownership of interfaces, compared with a point-to-point architecture (Guyot et al., 2007).

\section{Interoperability in PLM}

This section will study literature concerning the links between the different steps of the development of a product. We will focus on the interoperability view of those works to understand which level of interoperability is realized and with which methods. In the development phase, we distinguish three links that need to be analyzed:

- The design/ simulation information flow

- The design/manufacturing information flow

- The design/assembling information flow 
In the same way, the three levels of interoperability see before are used to classify the works:

- Technic level

- Semantic level

- Organizational level

From those criteria of analysis, we can construct a table to classify the works on this topic. The result of the analysis is synthetized in table 1 .

Table 1. Synthesis of bibliographical analysis

\begin{tabular}{|c|c|c|c|}
\cline { 2 - 4 } \multicolumn{1}{c|}{} & Semantic level & Technical level & Organizational level \\
\hline \multirow{2}{*}{ Design/simulation } & $\begin{array}{c}\text { (Nguyen Van, } \\
\text { 2006; Assouroko et al., } \\
\text { 2010; Charles, 2005) }\end{array}$ & (Troussier, 1999) & \\
\hline \multirow{5}{*}{ Design/manufacturing } & $\begin{array}{c}\text { (Le Duigou et al., } \\
\text { 2012; Paviot et al., } \\
\text { 2011; Ou-Yang and } \\
\text { Chen, 2003; Guyot et } \\
\text { al., 2007) }\end{array}$ & $\begin{array}{c}\text { Paviot et al., 2011 ) } \\
\text { (Martin, 2006; }\end{array}$ & (Laureillard, 2000) \\
\hline \multirow{2}{*}{ Design/assembling } & $\begin{array}{c}\text { (Demoly, 2010; Le } \\
\text { Duigou et al., 2012) }\end{array}$ & (Rejneri, 2000) & (Demoly, 2010) \\
\hline
\end{tabular}

\section{A. Design / simulation information flow}

The link between design and simulation is essential to the designers that based their technological choices on simulation analysis. Indeed the bidirectional flow of design and simulation can decrease the number of modifications between CAD and FEM models, decreasing the development time of the validated product model.

(Nguyen Van, 2006) defines architecture to facilitate the collaboration loops between design and simulation. He uses standard format to share information between those phases, ensuring the semantic flow conservation.

(Assouroko et al., 2010) proposes an approach for managing interoperability software CAD/CAE. To do so, he defines a model based on ontologies. To link the different ontologies, he defines a relations management method and tool.

(Charles, 2005) defines a simulation data management system to ensure the semantic flow between software. His model is based on STEP format.

(Troussier, 1999) uses the information contain in the calculation notes to determine the dependencies between the design and the simulation data. Her tool is based on a database that links the attributes of each simulation models to allow the designer to take into account the simulation data in his design model. 


\section{B. Design/manufacturing information flow}

The design/manufacturing link from the CAD to the CNC allows an optimized design for manufacturing. Moreover the interoperability between design and manufacturing allows propagating the information, avoiding costly backtracking.

(Ou-Yang and Chen, 2003) develops a high-level PDM/MRP integration framework. (Martin, 2006) proposes a Visual Basic tool to develop a mediator for the useful API in the link between design and casting.

(Guyot et al., 2007) or (Paviot et al., 2008) are interested in the problems of interoperability of CAD/PDM systems. Similarly (Paviot et al. 2011) proposes an unified approach for the interoperability of PDM/ERP systems. With the notion of mediator linking ontologies, he discusses the technical level. However, beyond the technical process, based on a model based on "semantic tags", he develops the semantic level of interoperability.

(Le Duigou al., 2012) deals with interoperability between design and manufacturing by defining a generic data model. He first uses a unified approach to model business specific models then he proposes a generic model integrating the specific models ensuring the semantic flow.

(Laureillard, 2000) deals with the link between design and manufacturing at organization level: "integration appears in the effective action of design through the combination of several factors, including the tool but also the organization or knowledge." The reconciliation between the different business actors promotes the exchange of information to increase knowledge for the conception of new systems.

\section{Design/assembling information flow}

The link between design and assembling essentially helps the designers in its approach of technical choices.

(Rejneri, 2000) develops an "offer of professional tools for designers of mechanical systems and are particularly interested in the assembly business." The tools developed are then able to help the designer in his choice allowing him to see a semi-automatic scenarios assembly and disassembly of the system. Through this tool it addresses the technical level of interoperability.

(Demoly, 2010) defines an assembly model Multi-Views Oriented (MUVOA) which aims to ensure the link between design and assembly. Semantic flow is thus ensured through the involvement of business actors, treating the problems of organizations.

Therefore, research to be explored in the short and medium term relate to the transition to a strategy and an essential component of PLM, which is the Manufacturing Process Management (MPM), which eliminates this challenge by integrating information on a single system. In fact, According to the Frost and Sullivan research firm (Keith Robinson, 2002), "Manufacturing Process Management $(M P M)$ software is its own unique category and provides links between upstream PLM software, such as computer-aided design (CAD) and Product Data Management $(P D M)$, and downstream applications, such as Enterprise Resource Planning (ERP)". 
In addition, the MPM responds to several challenges faced by business-critical today, including the need to shorten the time-volume, optimize production execution, ensure integration of information, allowing engineers, designers, and corporate staff to work interactively, etc.

\section{Conclusion}

This paper has presented technical and semantic barriers of interoperability, and the different approaches to solve the semantic level (integration, unification and federation). In addition, we presented our framework which focuses on interoperability between PDM-MPM-ERP systems.

In this article, we have not discussed how the different axes will be defined and specified, as well as technologies that will be used to implement them. This will be done in detail in the next stages of our work. However, due to our state of the art, very interesting and promising approaches such as Web technologies and ontologies approach of data exchange and interoperability software have been identified. They will certainly technology watches, see potential solutions to explore and use in the implementation of our approach.

\section{References}

Amann, K.: Product Lifecycle Management: Empowering the Future of Business. CIM Data Inc. (2002)

Assouroko, I., Boutinaud, P., Troussier, N., Eynard, B., Ducellier, G.: Survey on standards for product data exchange and sharing: application in CAD/CAE interoperability. International Journal of Design and Innovation Research 5(1) (2010)

ATHENA, Advanced Technologies for Interoperability of Heterogeneous Enterprise Networks and their Applications. FP6-2002-IST-1, Integrated Project (2003)

Benaben, F., Touzi, J., Rajsiri, V., Truptil, S., Lorré, J.P., Pingaud, H.: Mediation Information System Design in a Collaborative SOA Context through a MDD Approach. In: Proceedings of MDISIS 2008, pp. 89-103 (2008)

Booth, D., Haas, H., McCabe, F., Newcomer, E., Champion, M., Ferris, C., Orhcard, D.: Web Services Architecture. W3C Working Group. Note 11/2/2004 (2004)

Charles, S.: Gestion Intégrée des données CAO et EF - Contribution à la liaison entre conception mécanique et calcul de structures. PhD thesis, Université de Technologie de Troyes (2005)

Chen, D.: Framework for Enterprise Interoperability (2009)

Chen, D., Doumeingts, G.: European Initiatives to develop interoperability of enterprise applications - basic concepts, framework and roadmap. Journal of Annual Reviews in Control 27(2), 151-160 (2003)

Demoly, F.: Conception intégrée et gestion d'informations techniques: application à l'ingénierie du produit et de sa séquence d'assemblage. PhD thesis, Université de Technologie de Belfort-Montbéliard (2010)

EIF, European Interoperability Framework, White paper, pp. 1-40 (2004) 
Guyot, E., Ducellier, G., Eynard, B., Girard, P., Gallet, T.: Product data and digital mock-up exchange based on PLM. In: Proceedings of PLM 2007 Conference (2007)

Hoffman, P.: Similarité sémantique inter-ontologies basée sur le contexte. PhD thesis, Université Claude-Bernard Lyon 1 (2008)

IEEE. «Standard Computer Dictionary - A Compilation of IEEE Standard Computer Glossaries.» Standard Computer Dictionary - A Compilation of IEEE Standard Computer Glossaries, New York (1990)

INTEROP, Interoperability Research for Networked Enterprises Applications and Software, Network of Excellence, Proposal Part B (2003)

ISO 14258, Industrial Automation Systems- Concepts and Rules for Enterprise Models, ISO TC184/SC5/WG1, 1999-April-14 version (1999)

Kosanke, K.: ISO standards for interoperability: a comparison. In: Konstantas, et al. (eds.) Interoperability of Enterprise Software and Applications. Springer, London (2006)

Laureillard, P.: Conception intégrée dans l'usage Mise en œuvre d'un dispositif d'intégration produit-process dans une filière de conception de pièces forgées. PhD thesis, INPG (2000)

Le Duigou, J., Bernard, A., Perry, N., Delplace, J.C.: Generic PLM system for SMEs: Application to an equipment manufacturer. Int. J. Product Lifecycle Management 6(1), 51-64 (2012)

Martin, L.: Intégration du métier de la fonderie dans les processus de conception - méthodologies et outils associés. PhD thesis, Ecole Nationale Supérieure d'Arts Et Métiers (2006)

Nguyen Van, T.: Ingénierie système appliquée à la gestion des données techniques en entreprise étendue: Application aux boucle de conception / simulation. PhD thesis, Ecole Centrale Paris (2006)

Noel, F., Roucoules, L.: The PPO design model with respect to digital enterprise technologies among product life cycle. International Journal of Computer Integrated Manufacturing 21(2), 139-145 (2008)

Ou-Yang, C., Cheng, M.C.: Developing a PDM/MRP integration framework to evaluate the influence of engineering change on inventory scrap cost. Int. J. Adv. Manuf. Technol. (22), 161-174 (2003)

Paviot, T., Cheutet, V., Lamouri, S.: A PLCS framework for PDM/ERP interoperability. International Journal of Product Lifecycle Management 5(2-3-4), 295-313 (2011)

Paviot, T., Morenton, P., Cheutet, V., Lamouri, S.: MultiCAD/MultiPDM integration framework. In: 5th International Conference on Product Lifecycle Management, Seoul, Korea (2008)

Porter, M.: From competitive advantage to corporate strategy. Harvard Business Review, 43-59 (May/June 1987)

Pratt, M.J.: ISO 10303 : the STEP Standard for Product data Exchange and its capabilities. Int. J. Product Lifecycle Management 1(1), 86-94 (2005)

Rejneri, N.: Détermination et simulation des opérations d'assemblage lors de la conception de systèmes mécaniques. PhD thesis, Institut National Polytechnique de Grenoble (2000)

Robinson, K.: MPM Market Primed for Robust Growth (2002), http: / / www . promantechnology.com/mpm-plm.asp

Terzi, S., Bouras, A., Dutta, D., Garetti, M., Kiritsis, D.: Product lifecycle management - from its history to its new role. International Journal of Product Lifecycle Management 4(4), 360389 (2010) 
Troussier, N.: Contribution à l'intégration du calcul mécanique dans la conception de produits techniques: proposition méthodologique pour l'utilisation et la réutilisation. Thèse de doctorat de l'Université de Grenoble 1 (1999)

Tursi, A., Panetto, H., Morel, G., Dassisti, M.: Ontological approach for product-centrics information system interoperability in networked manufacturing enterprises. Annual Reviews in Control 33(1), 238-245 (2009)

Wegner, P.: Interoperability. ACM Computing Survey 28(1), 285-287 (1996)

Wiederhold, G.: Mediators in the architecture of future information system. IEEE Computer 25(3), 38-49 (1992) 